\title{
Effect of dietary phospholipid level on the development of gilthead sea bream (Sparus aurata) larvae fed a compound diet
}

\author{
I. SEILIEZ ${ }^{1}$, J.S. BRUANT ${ }^{2}$, J.L. ZAMBONINO INFANTE ${ }^{3}$, S. KAUSHIK ${ }^{1}$ \& P. BERGOT ${ }^{1}$ \\ ${ }^{1}$ INRA Fish Nutrition Laboratory, UMR NUAGE, St Pée-sur-Nivelle, France \\ ${ }^{2}$ Ferme Marine de Douhet, La Brée les Bains, France \\ ${ }^{3}$ IFREMER Centre de Brest, UMR NUAGE, Plouzané, France \\ Corresponding author : seiliez@st-pee.inra.fr
}

\begin{abstract}
:
The aim of the study was to determine the influence of dietary phospholipid (PL) levels on survival and development of first feeding gilthead sea bream (Sparus aurata) larvae. Larvae were fed from day 4 to 23 posthatching with an isoproteic and isolipidic formulated diet with graded levels of PL from 90$150 \mathrm{~g} \mathrm{~kg}^{-1}$ dry matter (DM). A dietary PL content of more than $90 \mathrm{~g} \mathrm{~kg}^{-1}$ DM seems to be necessary for sustaining growth of first feeding sea bream larvae. The survival rates of larvae fed the formulated diets (31-40\% at day 23 ) were similar to those generally observed in marine aquaculture hatcheries with live prey feeding sequence. However, this high survival rate was not associated with high growth and the larvae showed, at the end of the study, a high proportion of individuals with abnormal liver and calculi in the urinary bladder. It is concluded that although the diets used here cannot be used in total replacement of live preys, they constitute a solid starting point for further nutritional studies with first feeding gilthead sea bream larvae.
\end{abstract}

Keywords: Sparus aurata ; larvae ; phospholipids ; compound diet ; first feeding; development 
Effect of dietary phospholipid level on the development of gilthead sea bream (Sparus aurata) larvae fed a compound diet

I. Seiliez ${ }^{1}$, J.S. Bruant ${ }^{2}$, J.L. Zambonino Infante ${ }^{3}$, S. Kaushik ${ }^{1}$, P. Bergot ${ }^{1}$

${ }^{1}$ INRA Fish Nutrition Laboratory, UMR NUAGE, 64310 St Pée-sur-Nivelle, France

${ }^{2}$ Ferme Marine de Douhet - BP 4 - 17840 La Brée les Bains, France

${ }^{3}$ IFREMER Centre de Brest, UMR NUAGE, BP 70, 29280 Plouzané, France

\section{Corresponding author:}

Iban Seiliez

INRA Fish Nutrition Laboratory,

Unité mixte NUAGE

64310 St Pée-sur-Nivelle, France

Tel: (33) 559515999 ;

Fax (33) 559545152 ;

e-mail: seiliez@st-pee.inra.fr

Running title: Compound diet for first feeding sea bream larvae

Keywords: Sparus aurata ; larvae ; phospholipids ; compound diet ; first feeding; development 


\section{ABSTRACT}

The aim of the study was to determine the influence of dietary phospholipid (PL) levels on survival and development of first feeding gilthead sea bream (Sparus aurata) larvae. Larvae were fed from day 4 to day 23 post-hatching with an isoproteic and isolipidic formulated diet with graded levels of PL from 9 to $15 \%$ dry matter (DM). A dietary PL content of more than $9 \% \mathrm{DM}$ seems to be necessary for sustaining growth of first feeding sea bream larvae. The survival rates of larvae fed the formulated diets (31-40\% at day 23$)$ were similar to those generally observed in marine aquaculture hatcheries with live prey feeding sequence. However, this high survival rate was not associated with high growth and the larvae showed, at the end of the study, a high proportion of individuals with abnormal liver and calculi in the urinary bladder. It is concluded that although the diets used here cannot be used in total replacement of live preys, they constitute a solid starting point for further nutritional studies with first feeding gilthead sea bream larvae. 


\section{INTRODUCTION}

A high increase in farmed fish production is expected during the next few years. But fry availability is still a bottleneck for the development of marine aquaculture industry. For the moment, fry production in marine fish hatcheries relies on a live prey feeding sequence. The use of live prey presents several disadvantages such as high cost, low reliability in production and variable nutritional quality. Therefore, the main objective in fish larval nutrition is to formulate a compound diet that can be substituted for live prey as early as possible during larval development (Watanabe \& Kiron, 1994).

Recently, sustained good growth and survival (higher than that generally observed with live prey feeding) were obtained in European sea bass (Dicentrarchus labrax) fed exclusively compound diet from mouth opening (Cahu et al., 2003). However, for the gilthead sea bream Sparus aurata, in spite of research efforts devoted to the development of microdiets, it is still not possible to completely replace live prey during the first larval rearing phase (Fernandez-Diaz \& Yufera, 1997; Yufera et al., 2000; Robin \& Vincent, 2003; Robin \& Peron, 2004).

The suitability of an inert diet for larval fish depends on the characteristics of both diet and larvae, as well as the rearing system used. More specifically, recent studies have yielded some progress in understanding the behaviour, physiology and nutrition of larvae when fed inert diets (Yufera et al., 2000; Cahu \& Zambonino Infante, 2001). In this regard, the importance of dietary phospholipids $(\mathrm{PL})$ for growth and survival of larvae has been demonstrated by various studies (for review Coutteau et al., 1997). Initial studies of Geurden et al. (1995) showed that larval development is variably affected by dietary PL sources and levels. Recently, Cahu et al. (2003) showed that 
high dietary phospholipid level improved sea bass development and demonstrated that larvae have a high capacity to utilize phospholipids.

To explain the nature of the PL requirement and the role of these lipids during larval stage, several authors suggested the participation of PL in the intestinal absorption of neutral lipids (Coutteau et al., 1997; Fontagné et al., 1998; Salhi et al., 1999). Thus, by histological analysis of the anterior intestine of larval carp, it was demonstrated that lipid accumulation in enterocytes of fish fed PL-free diet was prevented by adding Phosphatidylcholine (PC) to the diet (Fontagné et al., 1998). The higher liver and hepatocyte volume of PC-fed fish confirmed the more important lipid export from the intestine when feeding PC. In analogy, feeding PC-rich diets to turbot resulted in higher levels of DHA in their lipid classes, as compared to fish fed the PC-poor and PL-deficient diets with the same amount of ethyl esters of polyunsaturated fatty acids (PUFA) (Geurden et al., 1998). In addition to a higher DHA content, the lipid of turbot and sea bass fed dietary PC also consisted of significantly higher amounts of triglycerides, in agreement with a higher neutral lipid uptake. All together, these findings confirm a specific role of PC shown before in an in vitro study on rat intestine, which indicated that PC stimulated the synthesis and secretion of the apoB48 protein of triacylglycerol-rich lipoproteins (Field and Mathur, 1995). The observed growth-promoting effect of PL can thus, at least partially, be explained by an increased energy flux from the intestinal mucosa towards the blood. A promoting effect of Phosphatidylinositol (PI) on initial development of fish larvae has also been observed but the role of this lipid class seems to be different to those of PC in that larvae fed PI-rich and PC-poor diets display high survival rate but lipid accumulation in enterocytes, indicating a poor neutral lipid uptake (Geurden et al 1998). Although it is now well accepted that PI and its metabolically active derivatives (namely inositol 
triphosphate and diacylglycerol) may regulate the protein kinase $\mathrm{C}$ activity and the maintenance of salt balances (Bell and Sargent, 1987), the exact nature of PI requirement is still not understood.

All together and in regard to the importance of PL for the initial development of fish larvae, the aim of the present study was to determine the influence of soy lecithin as a rich source of $\mathrm{PC}$ and $\mathrm{PI}(22 \%$ and $14 \%$, respectively) on the survival and development of first feeding gilthead sea bream larvae. For this purpose we took advantage of the progress made on inert diet development for European sea bass larvae (Cahu \& Zambonino Infante, 2001; Cahu et al., 2003). 


\section{EXPERIMENTAL PROCEDURES}

\section{Fish rearing and diets}

Eggs were obtained from natural spawning of gilthead sea bream (Sparus aurata) broodstock maintained at the Ferme Marine de Douhet fish farm (La Brée-les-Bains, France). Larval rearing was conducted at the Ifremer - Station de Brest and lasted 23 days. Newly hatched larvae were transferred from incubators to conical fibreglass tanks (35 litres) with black walls (initial stocking density of 120 larvae. $\mathrm{L}^{-1}$, i.e. 4200 larvae per tank). They were supplied with running sea water, which had been filtered through a sand filter, then passed successively through a tungsten heater and a degassing column packed with plastic rings. Throughout the experiment, the water temperature and salinity were $20{ }^{\circ} \mathrm{C}$ and $35 \mathrm{~g} . \mathrm{L}^{-1}$ respectively. Dissolved oxygen level was maintained above $6 \mathrm{mg} \cdot \mathrm{L}^{-1}$ by setting the water exchange up to $30 \%$ per hour (flow rate 0.18 litres $\mathrm{min}^{-1}$ ). The light intensity was $9 \mathrm{~W} / \mathrm{m}^{2}$ maximum at the surface. All animal procedures and handling were conducted in compliance with the Guide for the Care and Use of Laboratory Animals (National Research Council, 1985).

Larvae were distributed into eleven tanks before mouth opening (day 1 posthatching). Tank randomization was conducted at the start of the experiment; two tanks with larvae keep starved (negative control) and three tanks per dietary group. Larvae were fed from day 4 to day 23 post-hatching with dry microdiets (Table 1) formulated to contain $840 \mathrm{~g} \cdot \mathrm{kg}^{-1}$ of a basal mixture developed from a diet giving, in sea bass larvae, as good growth and survival results as live prey (patent WO0064273, 2000). In order to determine the influence of dietary phospholipid level without affecting fatty acids composition, diets of the three groups incorporated increasing levels of soybean lecithin (SDA, Marne la Vallée, France) and decreasing 
levels of soybean oil (Bouton d'Or, France) and were designated as PL8, PL12 and PL16 (Table 1). Microdiets were processed as follows: dietary ingredients were mechanically mixed with water, pelleted and dried at $50^{\circ} \mathrm{C}$ for $20 \mathrm{~min}$. The pellets were ground and sieved to obtain two sizes of particles; 75-150 $\mu \mathrm{m}$ used during the first 10 days, then 150-250 $\mu \mathrm{m}$ until the end of the experiment. Fish were continuously fed in excess for $18 \mathrm{~h}$ per day using a belt feeder.

Assayed composition of the diets was $\left(\mathrm{g} \cdot \mathrm{kg}^{-1} \mathrm{DM}\right)$ : Crude protein $509-524$; Crude fat $204-222$, differing only by the lipid source used (Table 1 ).

\section{Sampling and data analysis}

To monitor growth, thirty larvae per tank were taken once weekly from each tank. Larval body length was measured under a binocular microscope. Ten larvae per tank were also sampled on day $5,7,10,13,16$ and 19 and examined under a binocular microscope to determine several nutritional and physiological parameters such as the number of larvae having food in the digestive tract, the ingestion rate (IR) corresponding to the quantity of diet in the digestive tract, the liver morphology which become round and brown when degenerating, the presence of urinary calculi and spinal malformations, i.e. scoliosis, lordosis and coiled vertebral column. For monitoring IR, the following formula was applied for each tank: IR $=(\Sigma q /(3 \times N)) \times$ 100 with $q=$ quantity of diet in the digestive tract estimated with an arbitrary scale from 0 (no food) to 3 (maximum filling) and $\mathrm{N}=$ number of observations. The other mentioned criteria were determined in each tank as follows: (number of larvae with considered parameter $/ \mathrm{N}) \times 100$ with $\mathrm{N}=$ number of observations. Finally, at the end of the study (day 23), larval survival rates were determined by counting individuals. 


\section{Statistical analyses}

Results are given as mean \pm standard deviations. Percentage data were $\arcsin \left(\mathrm{X}^{1 / 2}\right)$ transformed before analysis. Diet-related differences were analyzed using one-way ANOVA followed by the Newman-Keuls multiple range test at the 0.05 significance level with the computing program STAT-ITCF (ITCF, 1988). 


\section{RESULTS}

\section{Larval survival and growth}

All the unfed larvae died by day 9-10 after hatching (data not shown). In contrast, 31 to $40 \%$ of larvae fed micro-diets survived to day 23 , but did not show statistical difference between diet treatments (Table 2). In contrast, the larval body length monitoring revealed differences between the three groups of fed larvae. At day 17, larvae fed PL8 were significantly smaller than those fed PL12 and PL16. However, the beneficial effect of high dietary phospholipid content on larval growth grew blurred thereafter and was not significant any more at day 23.

\section{Feeding incidence and physiological status}

The larvae ingested the diets from first feeding and continued to accept them throughout the experimental period irrespective of the diet (Fig. 1A). As soon as day $5,90 \%$ of fed larvae showed food in the gut. This percentage ranged from 90 to $100 \%$ up to day 10 and decreased in the second week of the experiment to reach $70 \%$ at day 19 . No significant difference was found between the three groups of fed larvae. The IR also reached a maximum level between day 5 and day 10 (ca 65\%) and decreased progressively in the second week of feeding to reach $38 \%$ at day 19 , with no statistical difference between the different fed groups (Fig. 1B). In contrast and as expected, the unfed group showed very low percentage of larvae with food in the gut and very low IR value (Figs. $1 \mathrm{~A}$ and 1B). The presence of food in the digestive track of unfed larvae is somewhat surprising and could be due to cannibalism between larvae as already observed in previous studies. However, all 
the unfed larvae died by day 9-10 after hatching indicating that this phenomenon has no incidence on larval development.

The morphology of liver, which is triangular and transparent in normal larvae and become round and brown when degenerating, was also monitored (Fig. 2). As expected, the percentage of unfed larvae showing abnormal liver was high as early as day 5 and reached $90 \%$ by day 7 . In contrast, in the fed groups, between days 5 and 16, the percentage of larvae with degenerated liver did not exceed $20 \%$. Nevertheless, the last sampled point (day 19) showed an increase of this percentage up to $30 \%$ revealing an aggravation of the physiological state of fed larvae irrespective of the diet at the end of the experiment.

It has been shown that the presence of urinary calculi induces severe mortality of sea bream larvae (Modica et al., 1993). The causes of calculi formation are not well understood but it seems that an in-adapted diet could contribute to their appearance. This physiological parameter was also monitored here (Fig. 3). As expected, the unfed larvae showed a high percentage of individuals with urinary calculi that reach $90 \%$ at day 10 (Fig. 3C). In the fed groups, the percentage of larvae with urinary calculi increased progressively, not exceeding $10 \%$ at day 5 and reaching values higher than $40 \%$ at day 19 . However, no significant difference was found between the three different fed groups.

Finally, spinal malformations such as scoliosis, lordosis or coiled vertebral column were monitored and irrespective of the group of larvae considered (fed or unfed) the percentage of larvae with skeletal malformation did not exceed $10 \%$ (data not shown). 


\section{DISCUSSION}

The present study described a feeding experiment of gilthead sea bream Sparus aurata larvae using exclusively dry microdiets. The previous attempts of compound diet feeding of gilthead sea bream larvae right from mouth opening have reported high mortality and poor growth (Yufera et al., 1999; Robin \& Vincent, 2003; Robin \& Peron, 2004). The determination of dietary requirement and the formulation of a diet for marine fish larvae represented for several years a major objective of many laboratories. In contrast, diet formulation has been easily achieved for some freshwater species larvae, which are bigger at hatching.

The tested diets, only differing by their lipid mixture composition, induced a survival rate (31-40\% at day 23) much higher than those obtained previously with exclusive dry microdiet feeding (Yufera et al., 1999; Robin \& Peron, 2004) and similar to that generally observed in marine aquaculture hatcheries with live prey feeding sequence. However this rather high survival rate was not associated with a high growth result. Indeed, sea bream larvae fed live prey can reach around $7 \mathrm{~mm}$ at day 17 (Chatain, 1994). This poor growth performance remains the main bottleneck for the use of dry microdiet for sea bream larvae feeding from mouth opening. Yufera et al. (2000) failed to obtain effective growth by using microcapsules as first food whereas they obtained high growth rate when microcapsules were fed to larvae after a few days of being fed Brachionus plicatilis. Similarly, two recent studies on sea bream larvae fed microdiets from mouth opening showed some but significantly lower growth compared to what could be obtained with live food (Robin \& Vincent, 2003; Robin \& Peron, 2004). Put together, these results indicate that the diets tested in this study as those of previous studies do not meet fully the nutritional requirement of first feeding 
sea bream larvae. In this regard, at the end of the present experiment, the larvae showed an increasing percentage of individuals with an abnormal liver and calculi in the urinary bladder (Figs. 2 and 3).

Several studies conducted on different fish species (Kanazawa et al., 1981; Shields et al., 1999) showed that fish do require dietary phospholipids, and that this requirement is higher in larvae than in juveniles (Kanazawa, 1993). In the present study, a significant difference appeared at day 17 in larval growth among the experimental groups. Indeed, PL8 fed larvae were significantly smaller than those fed PL12 and PL16. However, the beneficial effect of high soy lecithin contents on early larval growth was not significant any more at day 23. This was probably due to an aggravation of general state of larvae at the end of this period, also revealed by the high proportion of individuals with an abnormal liver and with calculi in the urinary bladder and by the decreasing percentage of larvae with food in the gut (Figs. 1-3). Therefore, the phospholipid content of PL8 diet seems to be limiting for the growth of first feeding sea bream larvae. This result is in agreement with those obtained in the European sea bass, showing that an amount of $11-12 \%$ of dietary phospholipid is needed and sufficient for a good development of larvae fed dry diet right from first feeding onwards (Grangier et al., 2001; Cahu et al., 2003). However, our results as those on sea bass were obtained with the use of phospholipid from vegetable sources (soy lecithin) and could be somewhat different with other PL sources especially those of marine origin rich in n-3 PUFA. Indeed, according to Sargent et al. (1999), some developmental promoting effect of PL are modulated by their fatty acid composition and marine PL appeared to be essential for fish larvae development. In the case of sea bass, the small amount of marine PL contained in fishmeal and fishmeal hydrolysate of the experimental diets was sufficient to allow good larval 
growth and survival (Cahu et al., 2003). Further studies will be necessary to demonstrate whether gilthead sea bream responds differently to different PL sources.

In conclusion, a dry microdiet sustaining a survival rate of $31-40 \%$, similar to that generally observed in marine aquaculture hatcheries with live prey feeding, has been formulated for the first time. This diet is efficiently accepted from the beginning of exogenous feeding. However, the larvae fed with these microdiets exhibited poor growth performance and increasing abnormalities in the end of the experiment. Therefore, although this diet cannot be used in total replacement of live preys, it constitutes a solid starting point for further nutritional studies. Besides the development of practical diets for juvenile production (Watanabe \& Kiron, 1994; Cahu \& Zambonino Infante, 2001), compound diets, and especially semi-purified diets, are useful tools to study the nutritional requirements in larval stages. Such an approach was successfully used in the nutrition of larvae of some fresh water species (RadünzNeto et al., 1994; Radünz-Neto et al., 1996) and since few years of marine fish species (Cahu et al., 2003).

\section{ACKNOWLEDGEMENTS}

This work was partially supported by a CIFRE grant (Ministry of Research and Ferme Marine de Douhet) to the first author. We are grateful to F. Cachelou (director of Ferme Marine de Douhet), Dr C. Cahu and Dr J.H. Robin (IFREMER, UMR NUAGE, Plouzané, France) for helpful discussions and encouragement. We thank $P$. Quazuguel and H. Le Delliou for their technical assistance, and D. Bazin for photographic provision. 


\section{REFERENCES}

Bell, M.V. \& Sargent, J.R. (1987) Protein kinase C activity in the spleen of trout (Salmo gairdneri) and the rectal gland of dogfish (Scyliorhinus canicula), and the effects of phosphatidylserine and diacylglycerol containing (n-3) polyunsaturated fatty acids. Comp. Biochem. Physiol. 87B, 875-880.

Cahu, C. \& Zambonino Infante, J. (2001) Substitution of live food by formulated diets in marine fish larvae. Aquaculture, 200, 161-180.

Cahu, C.L., Zambonino Infante, J.L. \& Barbosa, V. (2003) Effect of dietary phospholipid level and phospholipid: neutral lipid value on the development of sea bass (Dicentrarchus labrax) larvae fed a compound diet. Br. J. Nutr., $90,21-28$.

Chatain, B. (1994) Estimation et amélioration des performances zootechniques de l'élevage larvaire de Dicentrarchus labrax et de Sparus auratus. Thesis, Université d'Aix Marseille II, France.

Coutteau, P., Geurden, I., Camara, M.R., Bergot, P. \& Sorgeloos, P. (1997) Review on the dietary effects of phospholipids in fish and crustacean larviculture. Aquaculture, 155, 1-4.

Fernandez-Diaz, C. \& Yufera, M. (1997) Detecting growth in gilthead seabream, Sparus aurata L., larvae fed microcapsules. Aquaculture, 153, 93-102.

Field, F. G. \& Mathur, S. N. (1995) Intestinal lipoprotein synthesis and secretion. Prog. Lipid Res. 34, 185-198.

Folch, J., Lees, M. \& Sloane-Stanley, G.H. (1957) A simple method for the isolation and purification of total lipids from animal tissues. J. Biol. Chem., 226, 497509. 
Fontagne, S., Geurden, I., Escaffre, A. M. \& Bergot, P. (1998) Histological changes induced by dietary phospholipids in intestine and liver of common carp (Cyprinus carpio L.) larvae. Aquaculture, 161, 1-4.

Geurden, I., Raduenz-Neto, J. \& Bergot, P. (1995) Essentiality of dietary phospholipids for carp (Cyprinus carpio L.) larvae. Aquaculture, 131, 303-314.

Geurden, I., Bergot, P., Schwarz, L. \& Sorgeloos, P. (1998) Relationship between dietary phospholipid classes and neutral lipid absorption in newly-weaned turbot, Scophthalmus maximus. Fish Physiol. Biochem. 19, 217-228.

Grangier, V., Zambonino Infante, J., Quazuguel, P. \& Cahu, C. (2001) Effect of phospholipid, protein hydrolysate, and vitamin content on formulated diets for marine fish larvae, LARVI'01 - Fish \& Shellfish Larviculture Symposium. European Aquaculture Society, Ghent (Belgium).

ITCF (1988) STAT-ITCF, $4^{\text {th }}$ edn. Services des Etudes Statistiques, Paris.

Juaneda, P. \& Rocquelin, G. (1985) Rapid and convenient separation of phospholipids and non phosphorus lipids from rat heart using silica cartridges. Lipids, 20, 40-41.

Kanazawa, A. (1993) Essential phospholipids of fish and crustaceans. In: Fish Nutrition in Practice (Kaushik S.J. \& Luquet P. eds) pp. 519-530. IVth International Symposium on Fish Nutrition and Feeding, Paris (France).

Kanazawa, A., Teshima, S., Inamori S., Iwashita, T. \& Nagao, A. (1981) Effects of phospholipids on growth, survival rate and incidence of malformation in the larval ayu. Mem. Fac. Fish., 30, 301-309.

Modica, A., Santulli, A., Curatolo, A., Cusenza, L., Palillo, L. \& D'Amelio, V. (1993) Relationships between absence of functional swim-bladder, calculosis and 
larval mortality in hatchery-reared gilthead sea bream, Sparus aurata L. Aquacult. Fish. Manage., 24, 517-522.

National Research Council (1985) Guide for the Care and Use of Laboratory Animals. Publication $\mathrm{n}^{\circ}$ 85-23. Bethesda, MD: National Institutes of Health.

Radünz-Neto, J., Corraze, G., Charlon, N. \& Bergot, P. (1994) Lipid supplementation of casein-based purified diets for carp (Cyprinus carpio L.) larvae. Aquaculture, 128, 153-161.

Radünz-Neto, J., Corraze, G., Bergot, P. \& Kaushik, S.J. (1996) Estimation of essential fatty acid requirements of common carp larvae using semi-purified artificial diets. Arch Anim Nutr, 49, 41-48.

Robin, J.H. \& Vincent, B. (2003) Microparticulate diets as first food for gilthead sea bream larva (Sparus aurata): study of fatty acid incorporation. Aquaculture, 225, 463-474.

Robin, J.H. \& Peron, A. (2004) Consumption vs. deposition of essential fatty acids in gilthead sea bream (Sparus aurata) larvae fed semi-purified diets. Aquaculture, 238, 283-294.

Salhi, M., Hernández-Cruz, C.M., Bessonart, M., Izquierdo, M.S. \& FernándezPalacios, H. (1999) Effect of different dietary polar lipid levels and different $n-3$ HUFA content in polar lipids on gut and liver histological structure of gilthead seabream (Sparus aurata) larvae. Aquaculture 179, 253-263.

Sargent, J., McEvoy, L., Estevez, A., Bell, G., Bell, M., Henderson, J. \& Tocher, D. (1999) Lipid nutrition of marine fish during early development: current status and future directions. Aquaculture, 179, 217-229.

Shields, R.J., Bell, J.G., Luizi, F.S., Gara, B., Bromage, N.R. \& Sargent, J.R. (1999) Natural copepods are superior to enriched Artemia nauplii as feed for halibut 
larvae (Hippoglossus hippoglossus) in terms of survival, pigmentation and retinal morphology: relation to dietary essential fatty acids. J. Nutr., 129, 11861194.

Watanabe, T. \& Kiron, V. (1994) Prospects in larval fish dietetics. Aquaculture, 124, 223-251.

Yufera, M., Pascual, E. \& Fernandez-Diaz, C. (1999) A higly efficient microencapsulated food for rearing early larvae of marine fish. Aquaculture, $177,249-256$.

Yufera, M., Fernandez-Diaz, C., Pascual, E., Sarasquete, M.C., Moyano, F.J., Diaz, M., Alarcon, F.J., Garcia-Gallego \& M., Parra, G. (2000) Towards an inert diet for first-feeding gilthead seabream Sparus aurata L. larvae. Aquaculture Nutrition, 6, 143-152. 


\section{LEGENDS}

Fig. 1. Diet ingestion monitoring. (A) Percentage of larvae having food in the digestive tract at day $5,7,10,13,16$ and 19. (B) Ingestion rate (IR) of formulated diets at day $5,7,10,13,16$ and 19 calculated as described in experimental procedures. (C-F) Quantity of diet in the digestive tract estimated with an arbitrary scale from 0 (no food) to 3 (maximum filling).

Fig. 2. Evolution of the percentage of larvae with abnormal liver. The liver of sea bream larvae (red star), which is triangular and transparent in normal larvae $(A)$ and become round and brown when degenerating (B), was monitored at day 5, 7, 10, 13, 16 and $19(\mathrm{C})$.

Fig. 3. Evolution of the percentage of larvae with calculi in the urinary bladder. (A) urinary bladder (red star) without calculi. (B) urinary bladder with calculi. (C) Increase of the percentage of larvae with urinary calculi during the course of the experiment. 
Table 1. Diet formulation and composition

\begin{tabular}{lccc}
\hline Diet & PL8 & PL12 & PL16 \\
\hline Formulation $\left(g \cdot \mathrm{kg}^{-1}\right)$ & & & \\
Basal diet $^{\mathrm{a}}$ & 840 & 840 & 840 \\
Soyabean lecithin $^{\mathrm{b}}$ & 80 & 120 & 160 \\
Soyabean oil $^{\mathrm{c}}$ & 80 & 40 & - \\
& & & \\
Composition $^{\mathrm{d}}$ & & & 938 \\
Dry matter $^{\mathrm{g}}\left(\mathrm{g} \cdot \mathrm{kg}^{-1} \mathrm{DM}\right)$ & 958 & 952 & 524 \\
Crude protein $^{\mathrm{e}}\left(\mathrm{g} \cdot \mathrm{kg}^{-1} \mathrm{DM}\right)$ & 509 & 522 & 204 \\
Total lipids $^{\mathrm{f}}\left(\mathrm{g} \cdot \mathrm{kg}^{-1} \mathrm{DM}\right)$ & 222 & 208 & 149 \\
Phospholipids $^{\mathrm{g}}\left(\mathrm{g} \cdot \mathrm{kg}^{-1} \mathrm{DM}\right)$ & 89 & 110 & \\
\hline
\end{tabular}

a Basal diet (per kg diet): 400g fish meal, Sopropêche, France; $160 \mathrm{~g}$ yeast, Fromagerie Bel, France; $150 \mathrm{~g}$ soluble fish protein concentrate, CPSP G, Sopropêche, France; $80 \mathrm{~g}$ vitamin premix; $50 \mathrm{~g}$ mineral premix. Vitamin mixture $\left(\mathrm{g} . \mathrm{kg}^{-1}\right.$ vitamin mix): retinyl acetate, 1; cholecalciferol, 2,5; dl--tocopherol acetate, 10; menadione, 1 ; thiamin- $\mathrm{HCl}, 0.1$; riboflavin, 0.4 ; d-calcium panthothenate, 2; pyridoxine- $\mathrm{HCl}$, 0.3; cyanocobalamin, 1; niacin, 1; choline, 200; ascorbic acid (Iascorbyl-2-polyphosphate), 20; folic acid, 0.1; d-biotin, 1; meso-inositol, 30. All ingredients were diluted with a-cellulose. Mineral mixture $\left(\mathrm{g} \cdot \mathrm{kg}^{-1}\right.$ mineral mix): $\mathrm{KCl}$, 90; KI, 0.04; $\mathrm{CaHPO}_{4} \cdot 2 \mathrm{H}_{2} \mathrm{O}, 500 ; \mathrm{NaCl}, 40 ; \mathrm{CuSO}_{4} \cdot 5 \mathrm{H}_{2} \mathrm{O}, 3 ; \mathrm{ZnSO}_{4} \cdot 7 \mathrm{H}_{2} \mathrm{O}, 4$; $\mathrm{CoSO}_{4}, 0.02 ; \mathrm{FeSO}_{4} \cdot 7 \mathrm{H}_{2} \mathrm{O}, 20 ; \mathrm{MnSO}_{4} \cdot \mathrm{H}_{2} \mathrm{O}, 3 ; \mathrm{CaCO}_{3}, 215 ; \mathrm{MgOH}, 124 ; \mathrm{Na}_{2} \mathrm{SeO}_{3}$, $0.03 ; \mathrm{NaF}, 1$.

${ }^{\mathrm{b}}$ Soybean lecithin, DAFA LPR, SDA, France.

${ }^{c}$ Soybean oil, Bouton d'Or, France.

${ }^{\mathrm{d}}$ After drying at $105^{\circ} \mathrm{C}, 24 \mathrm{~h}$.

${ }^{\mathrm{e}}$ By the Kjeldahl method $(\mathrm{N} \times 6.25)$.

${ }^{f}$ Extracted according to Folch et al. (1957).

${ }^{9}$ By the Juaneda and Roquelin method (1985). 
Table 2. Survival and growth rates of gilthead sea bream larvae fed the experimental diets.

\begin{tabular}{lccc}
\hline Diet & PL8 & PL12 & PL16 \\
\hline $\begin{array}{l}\text { Survival (\%) } \\
\text { day 23 }\end{array}$ & $38 \pm 5$ & $40 \pm 2$ & $31 \pm 5$ \\
& & & \\
Total length (mm) & & & \\
day 4 & $3.5 \pm 0.2$ & $3.5 \pm 0.2$ & $3.5 \pm 0.2$ \\
day 10 & $4.0 \pm 0.1$ & $4.2 \pm 0.2$ & $4.1 \pm 0.2$ \\
day 17 & $4.7 \pm 0.0^{\mathrm{a}}$ & $4.9 \pm 0.2^{\mathrm{b}}$ & $5.0 \pm 0.1^{\mathrm{b}}$ \\
day 21 & $4.7 \pm 0.1^{\mathrm{a}}$ & $5.0 \pm 0.2^{\mathrm{a}}$ & $5.2 \pm 0.1^{\mathrm{b}}$ \\
day 23 & $5.0 \pm 0.2$ & $5.1 \pm 0.2$ & $5.3 \pm 0.1$ \\
\hline
\end{tabular}

${ }^{a, b}$ Mean values within a row with unlike superscript letters were significantly different $(P<0.05)$. 


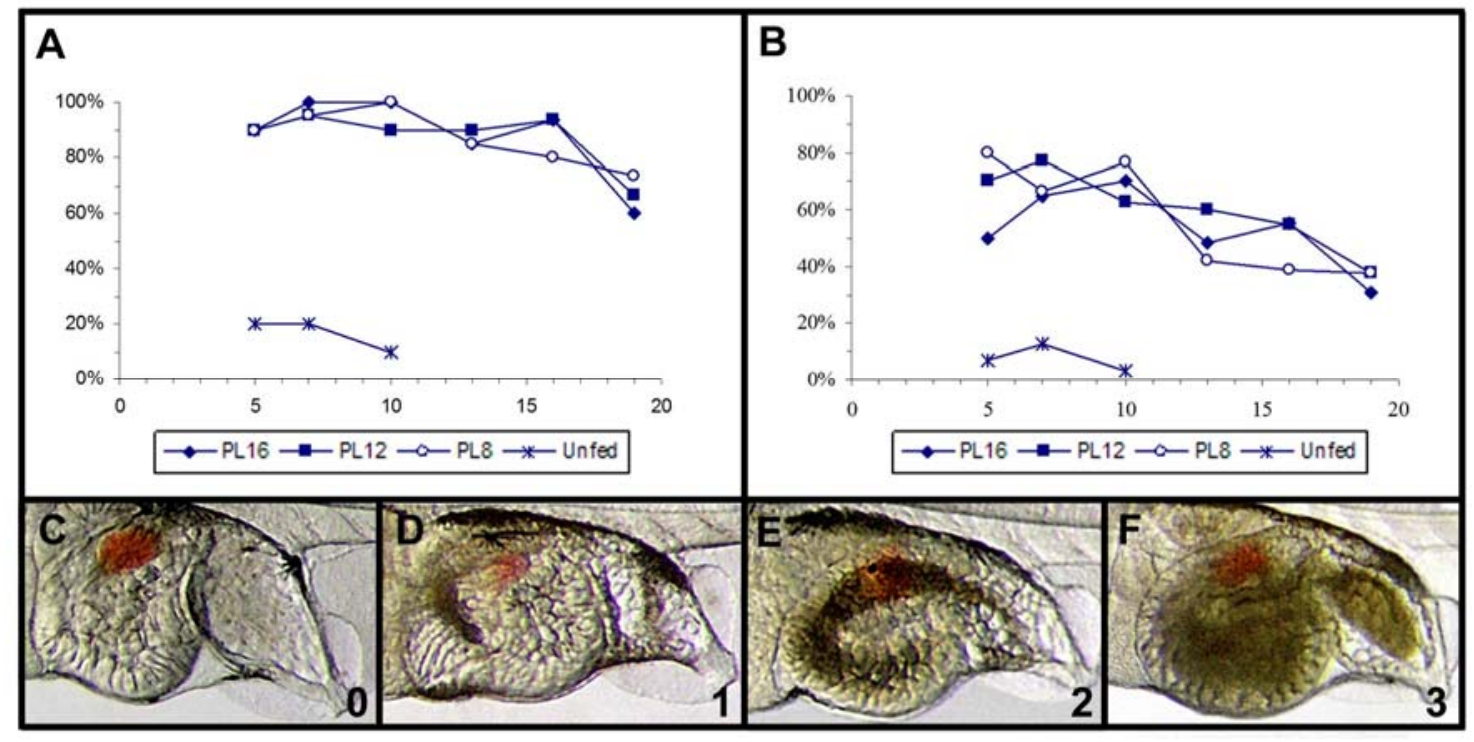

Seiliez et al., 1 


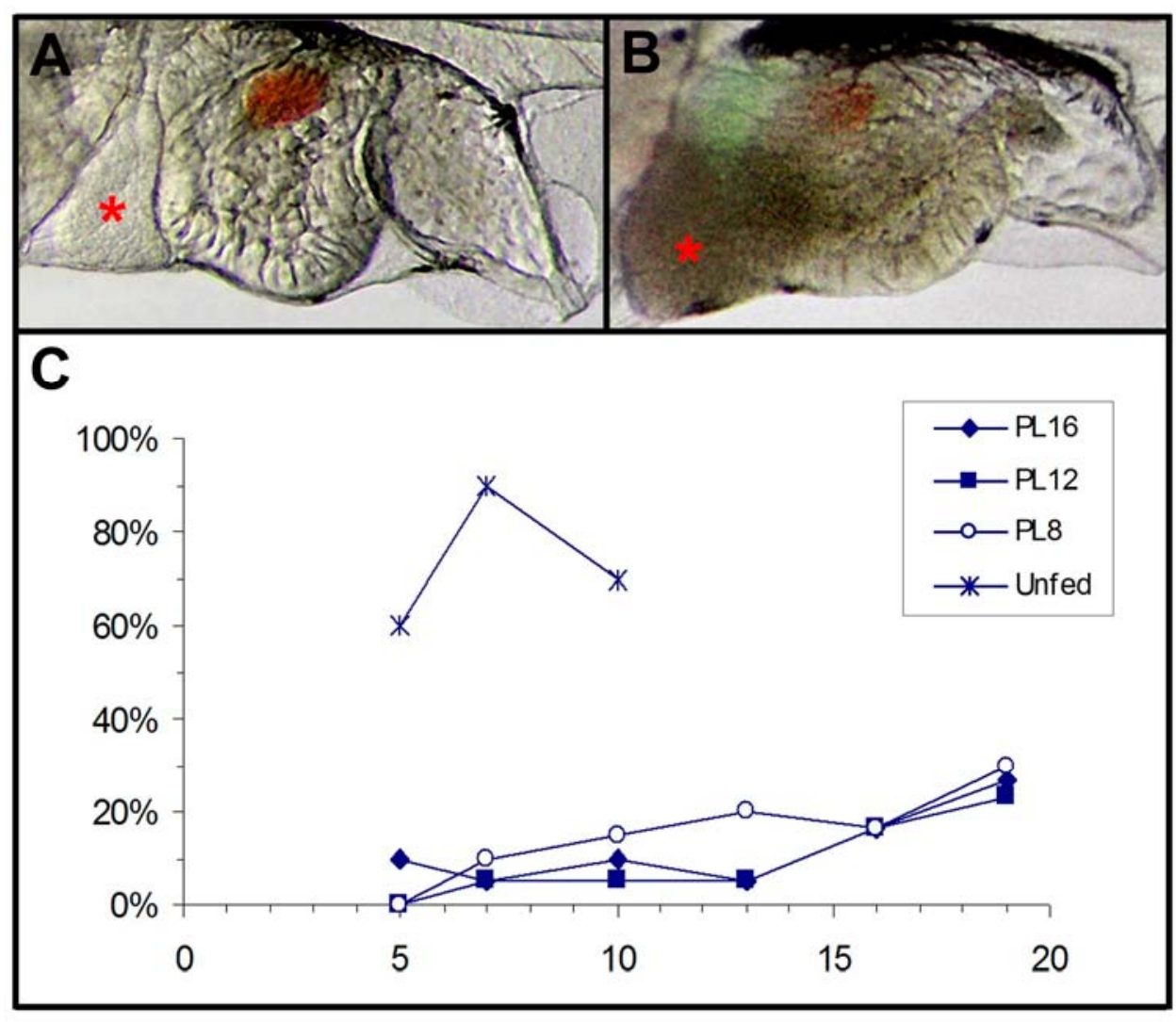

Seiliez et al., 2 


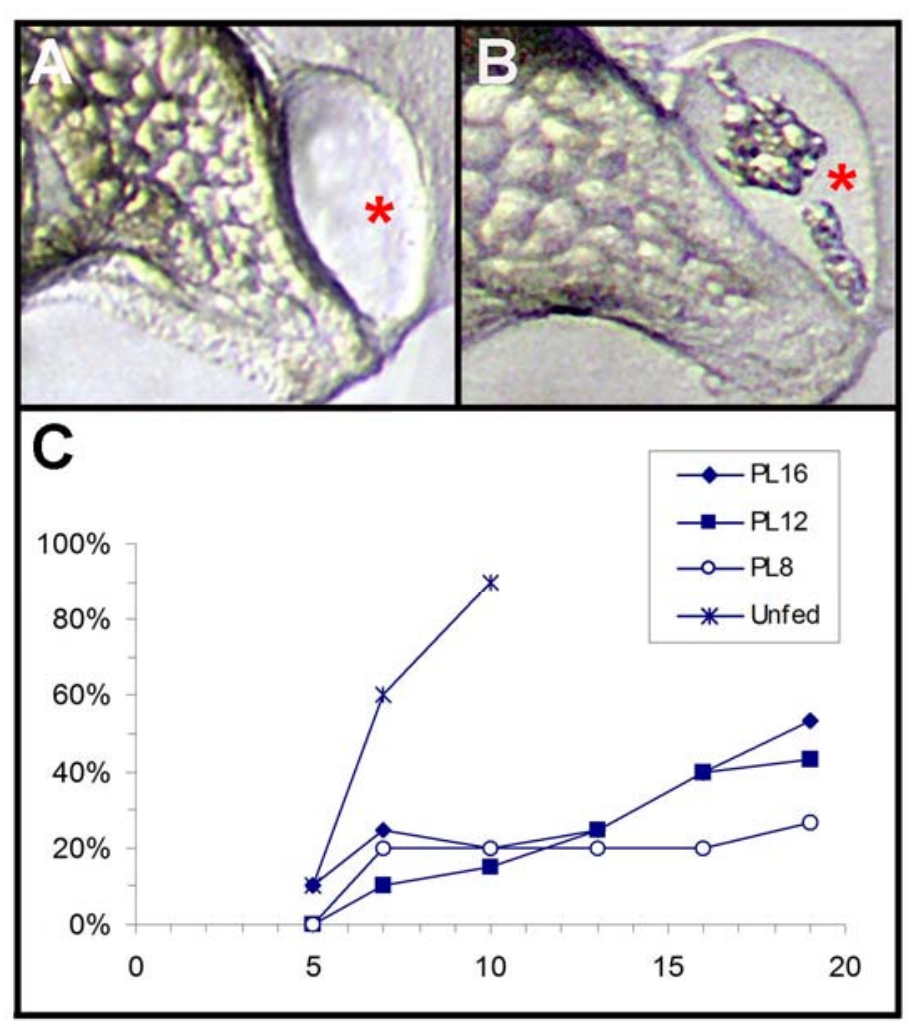

Seiliez et al., 3 